\title{
MULHERES NEGRAS E SUAS TRAJETÓRIAS EM BUSCA DA REPRESENTATIVIDADE
}

\author{
Marcela Duarte ${ }^{1}$ \\ Stephani Renata Gonçalves Alves ${ }^{2}$
}

\section{RESUMO}

Este artigo debate a questão de gênero e raça, abordando a feminilidade e a negritude. $\mathrm{O}$ percurso adotado parte do contexto histórico, trazendo elementos que dão conta de explicar como construiu-se a imagem da mulher negra até hoje e seus estigmas. A invisibilidade frente a publicidade se faz importante para demonstrar que ainda que haja uma grande parcela de mulheres negras, elas encontram obstáculos em se ver contempladas pelas mídias. As garantias legais da não discriminação de gênero e raça somam a este trabalho demonstrando que legalmente já existem dispositivos que asseguram a igualdade, porém não alcançam a realidade.

Palavras-chave: gênero e raça, feminismo, negritude, mulheres negras, publicidade, garantias legais.

\section{BLACK WOMEN AND THEIR PATH IN SEARCH OF REPRESENTATIVITY}

\begin{abstract}
This article discusses the issue of gender and race, addressing femininity and blackness. The path adopted starts from the historical context, bringing elements that explain how the image of black women was built up to date and their stigmas. The invisibility in front of advertising is important to demonstrate that even though there is a large portion of black women, they face obstacles in seeing themselves contemplated by the media. The legal guarantees of non-
\end{abstract}

\footnotetext{
${ }^{1}$ Mestranda em Direito pelo Programa de Pós Graduação em Direito, da Universidade La Salle, Canoas/RS. Graduada em Direito pela PUCRS. E-mail: marceladuarteadv@gmail.com.

${ }^{2}$ Mestranda em Direito pelo Programa de Pós Graduação em Direito, da Universidade La Salle, Canoas/RS. Graduada em Direito pela Faculdade Estácio de Porto Alegre/RS. E-mail: stephani_renata@hotmail.com.
} 
discrimination based on gender and race are added to this work, demonstrating that legally there are provisions that ensure equality, but they do not reach reality.

Keywords: gender and race, feminism, blackness, black women, advertising, legal guarantees.

\section{INTRODUÇÃO}

As discussões sobre gênero e raça têm sido mais presentes atualmente, já que muitos estudos sobre os dois temas têm surgido, assim como as discussões na academia. Este artigo tem como escopo a discussão envolvendo os temas de negritude e feminismo aplicados a representatividade. Buscou-se, através da pesquisa bibliográfica, dar conta de narrar, de maneira breve, a trajetória feminina das mulheres negras quanto ao empoderamento tão necessário para se desatar as amarras e a invisibilidade a que foram impostas.

Para discutir a representatividade, o enfoque se deu na questão das mídias e como a construção de um ideal não atingível esmaga a trajetória negra das mulheres nessa situação. Ter como padrão de beleza, aqui no Brasil, um modelo europeu é negar as características das mulheres brasileiras, que pouquíssimo têm relação com o continente do hemisfério norte.

O impacto desse modelo europeu intangível é grande, já que a publicidade entra com os objetos de desejos do povo, vendendo estereótipos inalcançáveis, gerando frustrações. Ainda que pese ter garantias legais, sabe-se que a discriminação, as vezes não percebida, já que se encontra na raiz de muitas estruturas sociais, está presente no cotidiano.

Assim sendo, este trabalho desenvolveu-se a partir do histórico do movimento de empoderamento das mulheres negras na sociedade brasileira, tendo por sequência a invisibilidade das mulheres negras na publicidade, culminando nas garantias legais da não discriminação.

\section{O MOVIMENTO DE EMPODERAMENTO DAS MULHERES NEGRAS NA SOCIEDADE}

A teoria do Empoderamento, nas palavras de Berth (2019), juntamente com os seus aspectos e as definições das opressões estruturais, as ferramentas utilizadas para opressões 
estruturais e a ligação inseparável do conceito e aplicação da teoria necessitam ser compreendidas para que se pense a respeito do conjunto que abarca o movimento do empoderamento das mulheres negras na sociedade. Portanto, o movimento feminista, que fora edificado ao decorrer da ruptura da concepção da universalidade da categoria mulher, ou seja, havendo uma nova concepção de um conjunto de mulheres através da proposição da interseccionalidade "mulheres negras, indígenas, latino-americanas e mulheres que não são brancas e outras", havendo uma reconstrução dos alicerces para uma nova visão e aplicação, assim como as brechas e as deturpações que precisavam de mais zelo. Sendo de suma importância para compreensão das desigualdades através do prisma de gênero e os lugares sociais das mulheres.

Chaves (2008) entende que para falar de mulheres negras, se faz necessária a utilização da categoria raça, mas ressalta que não há raças humanas e esta categoria não está ligada aos aspectos biológicos. É o termo de melhor compreensão para entender a dimensão do racismo uma vez que afeta diretamente a sociedade e os reflexos do racismo na representação de mulheres negras. Portanto, a utilização do termo raça abrange o desenvolvimento histórico e político, que fora referenciado cientificamente e dá início a um conjunto de desigualdade entre pessoas de forma absoluta. O racismo científico determinou a categoria raça com o objetivo de inferiorizar a população negra africana em comparação a pessoas brancas europeias, como forma de justificar a escravidão.

Tal qual Ribeiro (2019) explica, para falar das mulheres negras, deve-se compreender a construção colonizadora que implica na concepção de caminhos que devem ser trilhados por elas em um modo geral em que as mulheres não trilham o seu caminho, mas sim o caminho que é destinado a elas sob o prisma da figura masculina. Acresce que, o feminismo negro como movimento social, origina-se por contestar a categoria da mulher como singular.

Assis (2019) destaca que a categoria raça é utilizada para afirmar a diferença no tratamento quando a mulher é negra em uma sociedade que além de sexista é racista. Os movimentos feministas negros buscam denunciar que além da estrutura da nossa sociedade que despreza as mulheres, há um fator que potencializa a discriminação das mulheres negras através do racismo e seus marcadores sociais. 
Contudo, observa-se uma relação incômoda aos movimentos feministas de mulheres brancas e nas instituições mistas que faziam parte, ou seja, quando houve a ligação das categorias de gênero e raça, as mulheres negras eram sub-representadas. A modificação na situação das mulheres negras na sociedade através dos princípios base do feminismo negro é o questionamento que surge em vários aspectos e acaba por apontar como algo que irá enfraquecer as relações entre as mulheres, porém, na concepção das mulheres negras não há como ser feminista e também não lutar contra o racismo.

Através de uma sociedade colonizadora, as oportunidades foram geradas para determinados grupos sociais, dentro da concepção colônia se estabeleceu parâmetros e normas que favoreciam os colonizadores em ganhar proveito com a população negra. Segundo Chaves (2008), o racismo foi uma das ferramentas utilizadas na dinâmica colonial que inseriu estereótipos nas pessoas negras que são carregadas até a presente data. Contudo, as mulheres negras sofrem de maneira concreta com o surgimento da luta das mulheres para serem emancipadas socialmente, havendo uma desigualdade na participação de movimentos negros e das mulheres negras que não eram amparadas as suas pessoalidades raciais e de gênero. Por meio deste ponto começou-se uma nova discussão sobre os aspectos pessoais de cada mulher, não sendo possível uma luta só, mas uma luta em conjunto amplo.

Não obstante, Carneiro (2003) indica que houve uma concordância com vários movimentos sociais progressistas na sociedade brasileira e o feminismo durante um longo tempo permaneceu acorrentado dentro da concepção de valores europeus e universal das mulheres. O resultado foi uma inépcia de visualizar as diferenças e desigualdades no universo feminino, referente a identidade biológica. Deste modo, a invisibilidade e a estigmatização das mulheres negras e as diversas formas de opressão que vão além do sexismo se mantiveram silenciados.

Sendo assim, Assis (2019), esclarece que o feminismo tem como objetivo abordar os aspectos, de modo geral, da luta das mulheres, e que acima de tudo houve a urgência de estabelecer pontos específicos para representar grupos de mulheres, então, o feminismo negro surge para dar voz a essas mulheres e suas experiências de vida, por meio de suas lutas, no que tange principalmente a questão racial, que se debruça a uma série de opressões que as mulheres negras são submetidas diferentemente do que as mulheres brancas são expostas. $\mathrm{O}$ feminismo negro busca discutir as subordinações que as mulheres negras são impostas a 
suportar na construção de uma sociedade que determina padrões sociais que estão enraizados na cultura do Brasil. Há uma questão de muita relevância sobre esta construção social, pois as mulheres negras são mais suscetíveis a sofrer violência.

Nas palavras de Carneiro (2003), a violência se tornou um grande problema e as mulheres negras são os alvos. A violência doméstica e sexual é um problema que todas as mulheres enfrentam independentemente de sua cor ou classe social, mas, no entanto, se deve compreender que há um formato especifico de violência que reflete a distorção da imagem ou a uma representação positiva, causando uma limitação nas oportunidades de uma relação afetiva, a qual dificulta as relações de sexualidade, que são fruto de estigmas ao longo da história, frustrações no que tange a vida profissional, acarretando o flagelo a autoestima das mulheres negras.

Essa situação, no geral, é uma consequência da política de "branquitude", que está enraizada na sociedade e nas relações sociais que inviabiliza as violências que as mulheres negras são submetidas como reflexo de não pertencerem a um grupo racial que é estimulado como fosse o ideal. Portanto, as mulheres que não pertencem a este grupo têm a necessidade de, por meio de suas experiências, reescrever uma nova história.

Berth (2019) esclarece que o empoderamento consiste na junção de indivíduos que buscam desenvolver ou redesenvolver um processo contínuo, sendo um empoderamento prático que visa a coletividade, que demanda as modificações sociais que será de benefício de todos. Esclarece-se que o empoderamento luta contra um sistema dominador e as pessoas que procuram se aliar ao movimento de empoderação não podem se desviar da luta pelo coletivo.

De mesma maneira, Souza (2018) menciona que os grupos de mulheres negras são formados para dialogar, debater entre si e com a sociedade, para que haja uma compreensão de suma importância para aproximar as comunidades e os alicerces populares e que seja direcionado às mulheres negras e declarado que a crueldade que é refletida através do machismo, do sexismo e do racismo. Não adianta apenas tratar sobre as necessidades das mulheres negras, faz-se necessário e preciso demonstrar para toda a sociedade, de maneira que sejam propostas iniciativas públicas destinadas a mudanças na sociedade.

A expressão "Enegrecendo o Feminismo", conforme Carneiro (2003), vem sendo utilizada sobre o caminho trilhado pelas mulheres negras no movimento feminista brasileiro, o qual busca se diferenciar do clássico feminismo composto por mulheres brancas e ocidentais. 
E, em contrapartida, busca demonstrar a insuficiência da teoria e da prática de cunho político para mencionar os diferentes pontos do feminismo em uma sociedade plurirracial e multicultural, ou seja, a afirmação e a visibilidade dos reflexos do feminismo negro que tem como base a situação em que as mulheres negras, em sua grande maioria humildes, exercem na atuação de luta contra o racismo na sociedade brasileira.

De acordo com a Assis (2019), em seu estudo "O Feminismo Negro no Brasil e Interseccionalidade, os principais nomes do feminismo negro são Lélia Gonzales, Beatriz Nascimento, Neusa Santos Souza, Luiza Barros e Sueli Carneiro. A autora menciona que essas mulheres foram grandes símbolos do feminismo negro no Brasil.

Ainda de acordo com a autora (ASSIS, 2019), não é possível falar de feminismo negro sem destacar Lélia Gonzales, uma mulher negra que através de sua trajetória intelectual, sendo formada em História e Geográfia em 1958 e em Filosofia em 1962, militou pelos direitos das mulheres negras por meio do movimento negro filiado ao partido dos trabalhadores o qual se candidatou para o cargo de Deputada Federal em 1982. Lélia Gonzales, fora um marco na produção acadêmica por ressaltar as questões raciais na concepção da psicanálise.

Por sua vez, Beatriz Nascimento, historiadora, deixou sua marca sobre o estudo sexista e racista na concepção social partindo inicialmente dos quilombos ao longo da história. Já Neusa Santos Souza teve grande relevância na discussão sobre o racismo e classes sociais na sociedade brasileira, suas obras se tornaram grandes clássicos, e igualmente Luiza Bairros, que se tornou referência no que tange o diálogo direto com o feminismo negro americano e integrou a Secretaria de Política e Igualdade Racial como ministra no período de 2011 a 2014. Por fim, Sueli Carneiro é uma referência intelectual de grande relevância nos dias atuais e se debruçou nas condições das mulheres negras no Brasil (ASSIS, 2019).

Mediante o exposto, a colaboração que o feminismo negro teve na luta contra o racismo é de forma a demonstrar os efeitos do racismo e sexismo que aprisiona as mulheres negras a uma violação cruel e opressora da sociedade. No entanto, Assis (2019) relata que neste cenário a resistência e a garra das mulheres negras na luta por representatividade e pelo seu espaço social é notório. Elas buscaram demonstrar a luta de anos através de seu passado e continuando esta árdua batalha no presente a fim de quebrar tabus e ultrapassar as dificuldades. 
Assim, Ribeiro (2019) menciona que após a teoria Feminista, se pode falar do lugar de fala, mediante todas as reivindicações dos diferentes aspectos se compreendeu que o feminismo negro ressalta o seu lugar de fala e nota-se ser imprescindível esta necessidade para se visualizar o que até então não se havia conhecido explicitamente.

\subsection{O Empoderamento Das Mulheres Negras}

Primordialmente, ao questionar-se se a estética pertence ao empoderamento, de acordo com Berth (2019), deve-se compreender que os valores intrínsecos à estética estão interligados à imagem. Contudo, no seio da sociedade, sendo ela pluricultural e patriarcal, tendo como resultado drástico a desestimulação de grupos que ao longo da história são oprimidos. Uma vez que a sociedade impõe um padrão ideal de beleza, ela acaba por inferiorizar os perfis estéticos que não pertencem ao padrão idealizado. Conforme Gama e Olímpio (2018) dissertam o fato é que a estética negra é simbolizada como se fosse feia.

Corroborando, Carneiro e Ferreira (2014), explicam que a idealização do perfil biológico das mulheres brancas e jovens como a representação da beleza feminina demonstra a construção dos discursos racistas, sexistas e capitalistas. Gerando de certo modo uma inflexibilidade para aceitar outros padrões de beleza que são impostos pela sociedade e que se pode visualizar através da mídia em seus programas de TV e revistas. Se verifica que o símbolo de beleza imposto como perfeito é uma ligação direta referente a raça e a classes sociais, como também em outros pontos.

Berth (2019) entende que houve um processo histórico ao longo do tempo que oprimiu um grupo social e que refletiu na construção de padrões estéticos, sendo uma consequência da hierarquização das raças e gêneros resultando em dois grupos, o primeiro é o aceito e, em sequência, o não aceito devendo ser rejeitado com a finalidade de ressaltar o padrão que a sociedade impõe como ser o desejado.

Em que pese, Oliveira, Santos e Teixeira (2016), dissertam que há uma completude e um combate na compreensão no que tange as pessoas negras e se observa que a estética negra não segue o padrão de beleza de pessoas brancas. Portanto, este fato demonstra as relações dominantes na construção de estigmas das pessoas negras em comparação a pessoas brancas. 
Neste cenário, buscou-se, através do empoderamento das pessoas negras interligando à estética, o enaltecimento da beleza da população negra.

Ainda, seguindo o que Oliveira et al. (2018), traz sobre o tema, entende-se que é inquestionável o desprezo pela negritude, no decorrer dos séculos, havendo uma ilustração social no Brasil, que a pessoa negra é inferior, e que apenas o embranquecimento através da miscigenação ou terríveis tratamentos estéticos amenizariam de certo modo um pouco as características de ser uma pessoa negra.

De fato, Carneiro e Ferreira (2014) explicam que o branqueamento é normalmente compreendido como fosse a consequência do descontentamento de pessoas negras relacionado a sua aparência. Por este ponto, justificar-se-ia a procura por meio da miscigenação em diluir os traços negros ou por meio de tratamentos obterem a mudança de seus traços.

Nesta senda, Berth (2019) relata que as mulheres negras, de maneira consciente ou até mesmo inconsciente, quando passam por um tratamento capilar na busca de obter cabelos lisos estão na concepção das mulheres europeias idealizadas, ou seja, branca, que foi ilustrado pela colonização como o aceitável e correto. Esta procura por se encaixar no padrão resulta na sensação de fazer parte deste grupo e se sentir bem. Por outro lado, a manutenção e os cuidados que são necessários após o alisamento nos fios de cabelo são incômodos, entretanto, pelo conjunto de reforços sociais tem que se manter a aparência que fora ilustrada como a bonita, através de uma estrutura racista que desvaloriza as mulheres negras com todas as suas características.

Berth (2019) traz a passagem ilustrativa de uma situação muito comum das mulheres quanto aos cabelos ao afirmar que "ao se deparar com uma mulher branca de cabelos naturalmente lisos, se jogando no mar sem nenhuma amarra, a frustração irá alimentar o autoódio implantado e desenvolvido ao longo da História, mesmo que de forma involuntária".

Desta forma, Ferreira e Camargo (2011) trazem que a pessoa negra acaba por rejeitar os aspectos vindos de sua negritude e tenta reproduzir o molde que a sociedade considera ser o correto. Indo além, Winch e Escobar (2012) explicam que no Brasil, ser uma mulher negra, significa ser incluída em uma estrutura de marginalização e discriminação racial que está no cerne da sociedade. Mulheres negras acabam sofrendo uma duplicidade de preconceito, vinda de praxe do racismo e do sexismo. Em se tratando estar diante de uma mulher negra em 
condições de pobreza, o preconceito que ela carrega em seus ombros é muito maior, consequência de uma sociedade escravocrata que aprisiona as pessoas negras em rotulações de cunho discriminatório, sendo que no tocante a profissão, são destinadas geralmente para cargos de limpeza ou que explorem seus corpos. A mídia, por meio da publicidade entre outros, alimenta a concepção que as mulheres negras têm que se esforçar muito além do que as mulheres brancas para demonstrar sua competência e ganhar algum destaque.

Chama-se a atenção que, ainda que sejam muito sutis, as mulheres negras estão ganhando pequenos espaços nas mídias em gerais e tentando demonstrar outro ponto sobre a imagem que construíram das pessoas negras. Oliveira et al. (2018) descreve que até uma parte do século 20 a beleza branca era idealizada e definia os padrões estéticos a serem seguidos e os meios de comunicações, por sua vez, levavam esta ideologia para a sociedade como modo de inferiorizar as mulheres negras com seus traços africanos e ridicularizando os cabelos crespos.

Por conseguinte, pode-se analisar que o "cinema, o teatro, a televisão, a moda, a música, a dança” (BERTH, 2019) e qualquer outra demonstração de cunho artístico são de suma importância para se estabelecer um novo imaginário. No entanto, de acordo com Berth (2019), encontra-se um racismo atuante neste cenário em que a imagem é transmitida para o grande público e, por sua vez, as pessoas negras são excluídas juntamente com a sua arte por serem compreendidas como não sendo o padrão de beleza imposto. Assim, a pessoa negra ocupa um número menor de mídias e um lugar invisível em comparação com pessoas brancas. Não é possível não se emocionar, de maneira triste, quando há a representação negativa que neste ponto só serve para alimentar os estigmas já consistentes dos homens negros como delinquentes, das mulheres negras como mães pretas ou as mulatas fogosas como outras tantas máculas. Portanto, é inquestionável que o feminismo negro ou o movimento das mulheres negras no interior do feminismo sejam motivadores em restaurar o conceito e a afirmação do empoderamento.

Neste cenário, Carneiro (2003) aponta que a ascensão das mulheres negras, sendo no primeiro instante motivada pela busca da liberdade que se acorrentou no passado escravocrata e em um segundo momento se debruçou nas representações das mulheres negras e buscando nacionalmente estabelecer as figuras das mulheres negras que longo dos anos vem desempenhando papéis para novas concepções e ressaltando o passado que fora escondido. 


\section{A INVISIBILIDADE DAS MULHERES NEGRAS NA PUBLICIDADE}

A publicidade é a arte de criar desejos. O que será quisto por boa parte da população, qual será a nova maneira de se vestir, se roupas serão justas ou largas, confortáveis ou elegantes, se determinado produto estará em alta, se será o must have da estação, etc. Não precisa ser algo útil necessariamente. É por meio da publicidade que as pessoas divulgam marcas, produtos e ideias. Assim, é de se imaginar que o veículo de informação publicitário tenha como ponto de partida uma visão de pessoa base para quem se destina a maior parte dos produtos. Quando se pensa em um produto se pensa no tipo de consumidor que estará utilizando-se dele.

A etimologia da palavra entende que a construção se funda em público + dade, tornando o sentido para "caráter do que é público, conhecido, conjunto de meios utilizados para tornar conhecido um produto, uma empresa" (OXFORD, S.D). Em se tratando de publicidade, não se pode deixar de mencionar que a mesma se firma sobre o capitalismo. Quanto mais uma nação é capitalista mais ela consome, já que as coisas não são feitas para durar e depois de satisfeitas as necessidades básicas, existe a real necessidade de criar-se novas coisas para serem consumidas de maneira a nunca esgotar a máquina do capital (LINDSTROM, 2018).

É sabido que as campanhas publicitárias pensam em um público-alvo a ser atingido pelo produto que está sendo veiculado e que todos os movimentos feitos em prol da promoção do produto giram para o impulsionamento de vendas do mesmo. Há a necessidade do apelo emocional do público para que a persuasão seja eficaz e uma das maneiras utilizadas é a identificação, pois acredita-se que a mesma faz ponte com valores que sejam desejosos pelas pessoas que estão vendo.

No que tange as mulheres negras dois paradoxos são enfrentados: o gênero e a raça. Os movimentos feministas ainda necessitam reafirmar a igualdade que pregam, já que ainda há muita desinformação a respeito. A visão da mulher como sendo subserviente ao homem ainda impregna a sociedade como um todo. Não seria diferente na publicidade.

Silva (2019) afirma que as mulheres, em um contexto geral das peças publicitárias de revistas Veja que ela analisou entre os anos de 2002 e 2017, encontram-se em menor número 
de vezes, se comparado aos homens, que aparecem em 56\%. Também informa que ainda que tenha mulheres, as peças publicitárias tendem a estereotipar, primeiro importando um padrão europeu que praticamente é raro em terras brasileiras; em segundo, estabelecendo ligações com utilidades domésticas, produtos para casa ou algum produto em que as mulheres se mostrem como um objeto de conquista ou poder, como carros de luxo, passando a informação de "tenha um carro assim e tenha uma mulher assim".

Barkty apud Silva (2019) traz a ideia do patriarcado estabelecendo três direcionamentos fundamentais para a feminilidade: normas sobre tamanho e aparência do corpo - ser alta e magra como um ponto de partida -, regras a respeito do gestual e da postura das mulheres, sempre graciosas, e as normas sobre como produzirem-se, utilizando-se de maquiagem e adornos diversos como maneira de ornamentar os corpos. É a criação de um ser feminino ideal que, comparado ao que realmente encontra-se na sociedade, causa frustração, em maior ou menor grau.

Foucault entende o fenômeno como a dominação e a docilidade dos corpos provocada por instrumentos, ainda que não sendo físicos, reais e violentos, com foco nas práticas disciplinares modernas, reproduzindo uma tecnologia de autocontrole e vigilância entre os indivíduos. Tal prática, no que se reproduz oprime principalmente as mulheres, que vêm de um histórico de submissões (DANNER, 2010). No que trata sobre as mulheres negras, os dados de Silva são ainda piores. Mulheres negras perfazem um total de 5\% na pesquisa realizada pela doutoranda, levando em conta que mulheres negras brasileiras perfazem o total de $28 \%$ da população total do Brasil.

O Brasil aboliu a escravidão em 1888, por meio da Lei Áurea, entretanto, o real impacto de mais de 300 anos de escravidão ainda é visto no cotidiano por meio de práticas tão históricas que necessitam de intervenções para que se perceba que ainda se privilegia a branquitude em muitas situações. Se é através das peças publicitárias que se entende o ideal de sociedade que se busca, já que a sociedade capitalista é algo fático e estimulado atualmente, pois movimenta bilhões de reais, nota-se que as mulheres negras ficam em último lugar no quesito contemplação de propagandas. $\mathrm{O}$ mundo que se vende, é vendido em uma parcela muito pequena para as mulheres negras, visto que a publicidade ainda não se voltou para as mesmas de maneira a tratar com equidade frente as mulheres brancas. 
A estereotipização das mulheres negras, segundo Silva (2019), parece estar ligada à incapacidade de performance da feminilidade ideal, essa representada pelas mulheres brancas, ainda que sejam uma minoria na sociedade brasileira. Mulheres negras ainda são colocadas, de maneira proposital, em posições abaixo de mulheres brancas.

Se faz necessário lembrar que não há elementos que não sejam propositais em uma propaganda. São estudos que levam anos para dar aos profissionais os conhecimentos suficientes para atingir os objetivos de uma campanha publicitária. Cada parte da peça publicitária tem um estudo e reveste-se de valores que quer passar para o público.

As propagandas conseguem alcançar um significado que extrapola o das peças publicitárias em si. O que as pessoas querem consumir vêm carregado de valores que vão muito além do produto. Elas consomem todo um conjunto de concepções e convicções que estão atreladas ao objeto. Tal conduta tem sido demonstrada nos últimos anos ao perceber o boicote que algumas marcas sofrem por determinadas situações que ferem principalmente o princípio da não discriminação.

\section{AS GARANTIAS LEGAIS DA NÃO DISCRIMINAÇÃO}

Discriminar, segundo o dicionário Aurélio, é "tratar de forma injusta ou desigual uma pessoa ou um grupo de pessoas, por motivos relacionados com suas características pessoais específicas (cor de pele, nível social, religião, sexualidade etc.); excluir: o Estado discriminava os deficientes" (FERREIRA). Pensar sobre as garantias legais da não discriminação engloba pensar no princípio da igualdade, lecionado por Sarlet (2001) o qual entende que

\footnotetext{
Não sendo por outro motivo que a Declaração Universal da ONU consagrou que todos os seres humanos são iguais em dignidade e direitos. Assim, constitui pressuposto essencial para o respeito da dignidade da pessoa humana a garantia da isonomia de todos os seres humanos, que, portanto, não podem ser submetidos a tratamento discriminatório e arbitrário, razão pela qual não podem ser toleradas a escravidão, a discriminação racial, perseguições por motivo de religião, sexo, enfim, toda e qualquer ofensa ao princípio isonômico na sua dupla dimensão formal e material.
}

A Constituição Federal de 1988 (BRASIL, 1988) também tem, no seu preâmbulo, no artigo $3^{\circ}$, a presença da palavra igualdade, que também vai estar presente no artigo $5^{\circ}$, 
versando sobre os direitos fundamentais e no artigo $7^{\circ}$, no que se refere as melhorias em relação a condição social, entre outros dispositivos que se seguem e que têm como objetivo maior aquilo que pensou-se quando se fez uma nova Constituição naquela época, uma Constituição voltada aos cidadãos, que solucionasse problemas que vinham sendo notados anteriormente e que não conseguiam ser abarcados pelos dispositivos na época.

Enquanto princípio, a igualdade se estabelece tal qual um norte a ser perseguido, perpassando todas as esferas e incluindo-se em todas as situações. Não há como conceber uma sociedade sem que haja imbuída nela o ideal de igualdade de maneira que cada vez mais sejam vistos esforços para colocá-la em planos reais.

Outros documentos são importantes no âmbito nacional e internacional para garantir a não descriminação. Sendo da seara internacional:

- Declaração Universal de Direitos Humanos, 1948

- Pacto Internacional sobre Direitos Civis e Políticos, 1966 (Ratificado em 1992)

- Pacto Internacional Dir. Econômicos, Sociais e Culturais, 1966 (Ratificado em 1992)

- Convenção sobre a Eliminação de Todas as Formas de Discriminação contra a Mulher, 1979 (Ratificada pelo Decreto 4377/2002)

- Convenção Amer. de Direitos Humanos - Pacto de San Jose, 1969 (Ratificada pelo Decreto 678 de 1992)

- Carta Democrática Interamericana, 2003

- Convenção Interamericana para Prevenir, Punir e Erradicar a Violência contra a Mulher, “Convenção de Belém do Pará”. (Ratificada pelo Decreto 1973/1996)

- Convenção Interamericana para a Eliminação de todas as formas de Discriminação contra as Pessoas Portadoras de Deficiência (Ratificada pelo Decreto 3956/2001)

- Convenção 169 da Organização Internacional do Trabalho (OIT) sobre Povos Indígenas e Tribais, 1989 (ratificada pelo Decreto 5051, 2004)

- Convenção Interamericana contra toda forma de Discriminação e Intolerância, 2013

- Convenção Interamericana contra o Racismo, a Discriminação Racial e Formas Conexas de Intolerância, 2013. (MENDES, S.D).

Já no Brasil, além da supracitada Constituição Federal de 1988, tem-se as seguintes

Leis Federais:

- Código Penal

- Código de Processo Penal

- Lei 7.716/1989 - Lei dos Crimes de Preconceito e Discriminação (e Lei 9459/1997)

- Lei 8069/1990 - Estatuto da Criança e do Adolescente

- Lei 10.741/2003 - Estatuto do Idoso

- Lei 13.146/2015 - Lei Brasileira de Inclusão da Pessoa com Deficiência

- Lei 9029/1995 - Discriminação nas Relações de Trabalho

- Lei 12.288/2010 - Estatuto da Igualdade Racial

- Lei Anti-Terrorismo (Lei 13.260, 16/3/2016)

- Lei Geral da Olimpíada (Lei 13.284, 10/5/2016) 
- Lei Geral da Copa (Lei 12.663, 5/6/2012). (MENDES, S.D).

No que tange as mulheres negras, que é o foco dessa escrita, temos a mescla de dispositivos que dão conta da condição de gênero e de raça. Como já abordado anteriormente, estabeleceu-se que as mulheres possuem historicamente uma discriminação em relação a sua condição biológica. É válido lembrar que no final dos anos 50 ainda era necessário ser autorizada pelo marido para poder fazer viagens e que somente em 2002 se rompeu, no Código Civil, abandonando a figura da relativa incapacidade da mulher presente no rol de hipóteses, igualando-as a menores e dezoito anos e maiores de dezesseis, ébrios habituais, viciados em tóxicos e deficientes mentais com discernimento reduzido do Código de 1916.

Entende-se que o distanciamento de 1916 até 2002, quase cem anos, fez com que inúmeras conquistas femininas se colocassem entre as datas. Um movimento feminista forte se fez presente em muitas nações. As mulheres conquistaram o direito de exercer sua escolha política através do voto, o direito de buscar um emprego, divorciar-se, se assim desejassem, entre outros.

Em especificidade das mulheres negras, vê-se um movimento que faz a união das lutas de gênero e raça e em ambas há o suporte das leis e da doutrina para que haja igualdade. Entretanto, tal posicionamento não consegue dar conta da realidade. Mulheres negras ainda sofrem duplamente pelas condições de gênero e de raça. São, historicamente, as que menos recebem salários. Ainda que sejam mais de $28 \%$ da população total do Brasil não encontram na publicidade uma identificação para com a sua imagem. Por mais que se tenha leis que tentem dar conta de garantir a não discriminação, o colocar em prática nas situações mais específicas acaba por não contemplar tal porção populacional.

As leis foram feitas para garantirem direitos e exigir deveres dos cidadãos que vivem sobre aquela égide. No Brasil, a igualdade é um dos pilares da Constituição. Tem-se outras tantas leis específicas que tentam dar conta da eliminação de ações discriminatórias mas ainda assim se encontra a discriminação velada, que se mistura a estrutura da sociedade e que gera prejuízos incalculáveis.

\section{CONSIDERAÇÕES FINAIS}


Ao decorrer deste trabalho, pode-se observar o doloroso caminho que as mulheres negras percorreram em uma sociedade que as estigmatizou, não só pelo fato de serem negras, mas por serem mulheres e negras. A sua invisibilidade perante a sociedade reflete em uma série de atos discriminatórios e desiguais fazendo com que no caminho das mulheres negras houvesse mais espinhos do que rosas presentes, sendo necessário lutar arduamente por seus espaços na sociedade e por políticas públicas para que de fato a igualdade da população negra fosse garantida. Como verificado na primeira parte, o movimento de empoderamento da mulher negra na sociedade demonstrou que as suas condições de desigualdade social que são derivadas de um racismo enraizado na sociedade brasileira.

Por sequência, abordou-se o Empoderamento das mulheres negras no que tange a necessidade em autoafirmar-se não apenas quanto a sua existência, mas a beleza existente em seus traços, independentemente do padrão europeu que durante séculos representou-se como símbolo de beleza. No terceiro ponto, averiguou-se a invisibilidade das mulheres negras na publicidade, que durante anos não conseguiram sentir-se representadas nas campanhas publicitárias por serem consideradas e exaltadas de uma beleza fora do padrão desejado. E por fim, foram elencadas as garantias legais da não discriminação, analisando e descrevendo os dispositivos e seus princípios legais que repudiam todos e quaisquer atos discriminatórios, mas o que mais salienta-se do estudo é que de fato a realidade enfrentada ainda dos dias de hoje é a da discriminação e representações de cunho racista e degradante em relação as mulheres negras.

\section{REFERÊNCIAS BIBLIOGRÁFICAS}

ASSIS, Dayane N. Conceição de. Interseccionalidade. Salvador: UFBA, Instituto de Humanidade, Artes e Ciência; Superintendência de Educação a distância, 2019.

BERTH, Joice. Empoderamento. Coleção Feminismos Plurais. Coordenação Djamila Ribeiro. São Paulo: Jandaíra, 2019.

BRASIL. Constituição da República Federativa do Brasil (1988). Disponível em: http://www.planalto.gov.br/ccivil_03/constituicao/ConstituicaoCompilado.htm. Acesso em 20 de dezembro de 2020.

CARNEIRO, Anni, Novais de. FERREIRA, Silvia Lúcia. Padrões De Beleza, Raça E Classe: Representações E Elementos Identitários De Mulheres Negras Da Periferia De 
Salvador-BA. $18^{\circ}$ Redor, Conferência.2014- Universidade Federal Rural de Pernambuco. Recife-PE. Disponível em:

http://www.ufpb.br/evento/index.php/18redor/18redor/user/account. Acesso em 13 de dezembro de 2020.

CARNEIRO, Sueli. Mulheres Em Movimento. Estud. av. Vol. 17, n. 49, São Paulo. Sept/Dec.2003. Disponível em:

https://www.scielo.br/scielo.php?script=sci_arttext\&pid=S0103-40142003000300008. Acesso em 10 de dezembro de 2020.

CHAVES, N. M. As Lutas Das Mulheres Negras: Identidade E Militância Na Construção Do Sujeito Político. 2008. 118 F. Dissertação (Mestrado em História) - Universidade de Brasília- UnB, Brasília, 2008.

DANNER, Fernando. O Sentido da Biopolítica em Michel Foucault. Revista Estudos Filosóficos. No 4 /2010 - versão eletrônica - ISSN 2177-2967 DFIME - UFSJ - São João delRei-MG. Pág. 143 - 157. Disponível em: http://www.ufsj.edu.br/revistaestudosfilosoficos.

Acesso em 02 de dezembro de 2020

FERREIRA, Aurélio Buarque de Holanda. Dicionário da língua portuguesa. Disponível em: https://www.dicio.com.br/ Acesso em 15 de dezembro de 2020.

FERREIRA, Ricardo Frankllin. CAMARGO, Amilton Carlos. As Relações Cotidianas E A Construção Da Identidade Negra. Psicol. Cienc. Prof.[ online].2011, vol.31, n², pp.374389. Universidade Federal do Maranhão. Disponível em: https://www.scielo.br/scielo.php?script=sci_abstract\&pid=S141498932011000200013\&lng=en\&nrm=iso\&tlng=pt. Acesso em 15 de dezembro de 2020.

GAMA, Isabela Caroline Aguiar de. OLÍMPIO, Ramon. O Peso Do Racismo Sob Estética Da Mulher Negra: Paradoxo Da Isonomia Social Brasileira. Congresso Brasileiro de Pesquisadores Negros. 10 ed. 2018- Universidade Federal de Uberlândia. Disponível em: https://www.copene2018.eventos.dype.com.br/resources/anais/8/1527707080_ARQUIVO_art igo-isabelagama-doc.pdf. Acesso em 10 de dezembro de 2020.

LINDSTROM, Martin. A lógica do consumo: verdade e mentiras sobre por que compramos. Nova Iorque: Harper Collinns, 2018.

MENDES, Conrado Hübner. Direito da Anti-Discriminação Brasileiro. Curso Direito e Discriminação. Disponível em: http://biton.uspnet.usp.br/ddd/wpcontent/uploads/2017/01/Direito-anti-discriminac\%CC\%A7a\%CC\%83o-direitos.pdf. Acesso em 12 de dezembro de 2020.

OLIVEIRA, Crysia Mayara De. et al. A quebra do padrão de beleza: a aceitação da mulher negra na sociedade. E-book SINAFRO... Campina Grande: Realize Editora, 2018. p. 178-185. Disponível em: https://editorarealize.com.br/artigo/visualizar/39565. Acesso em: 18 de dezembro de 2020. 
OLIVEIRA, Natália Gogofredo de. SANTOS, Maria Anselmo dos. TEIXEIRA, Vanessa Ribeiro. Mulher Negra, Cabelo E Empoderamento: Uma Análise Do Seriado Sexo E As Negas. II Congresso Internacional de Linguística e Filologia, XX Congresso Nacional de Linguística e Filologia. Caderno do CNLF, vol. XX, n 01 - Análise do Discurso, Linguístico textual e pragmático. Rio de janeiro: Ciffil, 2016.

OXFORD LANGUAGES. Etimologia da palavra publicidade. Disponível em: https://languages.oup.com/google-dictionary-pt. Acesso em 10 de dezembro de 2020.

RIBEIRO, Djamila. Lugar De Fala. Coleção Feminismos Plurais. Coordenação Djamila Ribeiro. São Paulo: Jandaíra, 2019.

SARLET, Ingo Wolfgang. Dignidade da Pessoa Humana e Direitos Fundamentais. Porto Alegre: Livraria do Advogado, 2001. p. 89.

SILVA, Marcelle Barreto Felix da. Representatividade negociada: feminilidade, raça e gênero na publicidade. Revista Brasileira de História da Mídia. Vol. 8. № 2. jul./dez. 2019.

SOUZA, Grace Silva sobral. Mulheres Negras: Memória Da Trajetória De Luta E Resistência Dos Movimentos De Mulheres Negras Do Maranhão A Partir Do "Grupo De Mulheres Negras Mãe Andressa”. Kwanissa, São Luis, v.1, n.1, 154-172, jan/jun. 2018. Disponível em:

http://www.periodicoseletronicos.ufma.br/index.php/kwanissa/article/viewFile/8632/5286 Acesso em 08 de dezembro de 2020.

WINCH, Rafael Rangel. ; ESCOBAR, Giane Vargas. Os Lugares Da Mulher Negra Na Publicidade Brasileira. Caderno de comunicação. v.16, n², jul/Dez.2012. Universidade Federal de Santa Maria- UFSM. Disponível em:

https://periodicos.ufsm.br/ccomunicacao/article/view/8229. Acesso em 15 de dezembro de 2020. 